\title{
OFICINAS DE PARENTALIDADE: EFICIÊNCIA E EFICÁCIA NA ATENUAÇÃO DO FENÔMENO DA ALIENAÇÃO PARENTAL ${ }^{1}$
}

PARENTALITY WORKSHOPS: EFFICIENCY AND EFFECTIVENESS IN ATTENUING THE PARENTAL ALIENATION PHENOMENON

Júlia Tuzzi BORINI ${ }^{2}$

Roberta dos Santos Pereira de CARVALHO ${ }^{3}$

ISSUE DOI: 10.21207/2675-0104.2019.933

\section{RESUMO}

As oficinas de parentalidade são encontros realizados com pais em processo de divórcio litigioso, seus filhos, psicólogos, conciliadores e mediadores do CEJUSC. O objetivo principal é amenizar o número de casos de alienação parental. Os pais são instruídos sobre as consequências psicológicas de atitudes alienadoras e, as crianças, sobre os sinais indicadores de pais alienantes, bem como sobre as atitudes a serem tomadas nesses casos. Sem apoio financeiro, as oficinas, hoje, não possuem forças para grande

\footnotetext{
${ }^{1} \mathrm{O}$ presente artigo sintetiza a monografia de conclusão da pesquisa, realizada para o Programa Interno de Bolsas de Iniciação Científica (PIBIC 2018-2019) da Faculdade de Direito de Franca (FDF), Franca/SP.

${ }^{2}$ Discente da Faculdade de Direito de Franca (FDF), Franca/SP. Bolsista do Programa Interno de Bolsas de Iniciação Científica (PIBIC 2018-2019).

${ }^{3}$ Possui graduação em Direito pela Universidade Estadual Paulista Júlio de Mesquita Filho (1993) e mestrado em Direito das Relações Econômico Empresariais pela Universidade de Franca (2003). Atuou como professor titular da Universidade de Franca - UNIFRAN, até junho de 2008. Atualmente execer a docencia junto ao Centro Univesitário da Fundação Educacional Guaxupé-MG e na Faculdade Dr. Francsico Maeda- FAFRAM, em Ituverava-SP. Presta Serviços como Professor Colaborador da Faculdade de Direito de Franca-SP. Tem experiência na área de Direito Público, com ênfase em Direito Penal e Direito Processual Penal. Contato: bettacarvalho@gmail.com.
} 
expansão. A presente pesquisa visa analisar a eficiência e a eficácia das oficinas de parentalidade, de forma a apontar a relevância da expansão do projeto.

Palavras-chave: Oficinas de Parentalidade; Alienação Parental; divórcio litigioso; CEJUSC.

\begin{abstract}
The parenting workshops are meetings with parents that are going trough a complicated divorce, their kids, psychologists, conciliators and mediators from CEJUSC. The main goal is to mitigate cases of parental alienation. The parentes get instructed about the psycological consequences of their actions on their children and the children about how to identify signs of alienation and what to do about it. With no financial support, the workshops do not have enough strength to expand. This resarch will analyse the efficiency and efficacy of the parenting workshops, in a way to understand the relevance of the project's expansion.
\end{abstract}

Keywords: Parental workshops; Parenting alienation; Litigious divorce; CEJUSC.

\title{
$1 \quad$ INTRODUÇÃO
}

A alienação parental é uma conduta proveniente de um dos genitores ou do guardião, na medida em que este denigre constantemente a imagem do genitor ausente. Tendo o detentor da guarda um convívio notavelmente mais constante com a criança do que qualquer outra pessoa, é compreensível que suas falas e atitudes venham a ter mais influência no comportamento do menor.

$\mathrm{Na}$ fase judicial da separação, momento de extrema importância para as decisões acerca do futuro dos filhos, os pais, carregados de sentimentos negativos um em relação ao outro, em regra, não encontram acordo, de forma que a responsabilidade de decidir o melhor para a criança fica para o Magistrado, pessoa essa que conhece superficialmente o menor ou até mesmo nem conhece,

É nítido que a supremacia de uma opinião de terceiro não interessado nem sempre coincide com o melhor para o interesse do menor.

Diante de tal problemática, percebeu-se a necessidade de dinâmicas e conversas com aqueles que dividem ou dividirão a guarda e com os menores que veem sua vida dividida. Foi então que o CEJUSC (Centro Judicial de Solução de Conflitos) passou a realizar as Oficinas de Parentalidade.

Tais oficinas surgiram nos Estados Unidos e Canadá, tendo sido trazidas para o Brasil pela juíza Vanessa Aufiero da Rocha, quem implementou o projeto inicialmente na comarca de São Vicente/São Paulo. 
Diante da grande aceitação, o CNJ (Conselho Nacional de Justiça) o adotou como política institucional, determinando que as oficinas fossem um dos recursos utilizados pelos CEJUSCs.

O objetivo é que, em todo o país, participem das oficinas aqueles que se encontram em situação de divórcio crítico. Para tanto, faz-se uma triagem dos processos do âmbito familiar a fim de selecionar aqueles que apresentam probabilidade de alienação parental. As demandas que envolverem menores entre 06 e 17 anos deverão ser encaminhados para as oficinas, selecionando-se aqueles que aparentam real necessidade de intervenção.

Em algumas poucas comarcas brasileiras, essas dinâmicas já ocorrem. Comandadas pelo CEJUSC, as oficinas de parentalidade dependem exclusivamente de voluntários e da cessão gratuita de espaços físicos, de forma que, sem financiamento pelo Estado, são grandes os obstáculos para manutenção e expansão enfrentados pelos conciliadores, mediadores e psicólogos que fazem o projeto funcionar.

Por esses motivos, pouco se sabe a respeito dos reais resultados que as oficinas trazem, o que, somado à restrita divulgação, gera no judiciário certo receio de implementação em novas comarcas.

Para realização da presente pesquisa, inicialmente, foi feita a leitura de teses e outros materiais diversos a respeito do tema Alienação Parental. Após, procedeu-se ao recolhimento e análise das cartilhas utilizadas nos cursos preparatórios dos voluntários, de onde foram extraídas informações essenciais a respeito do funcionamento do projeto.

Ainda no aspecto teórico, foi realizado o estudo de sentenças e acórdãos que decidem sobre a alienação parental, analisando a guarda e a esquematização de visitas que foram aplicadas.

Por fim, para melhor compreender a dinâmica do projeto, houve participação em duas oficinas de parentalidade, momento em que foi possível formular perguntas para os organizadores e observar o efeito causado nos participantes.

\section{ALIENAÇÃO PARENTAL}

Na década de 70, nos Estados Unidos, o judiciário observou a necessidade de avaliação do estado de crianças que se recusavam a manter 
contato com o genitor não detentor da guarda. Nesse contexto, Richard Gardner, psiquiatra norte - americano, percebeu um complexo de sintomas comportamentais, manifestados por crianças, os quais denominou de Síndrome de Alienação Parental (SAP), a qual tem como consequência a alienação parental.

Para Figueiredo e Alexandridis (2011p. 46), a alienação parental é:

\begin{abstract}
um fenômeno que geralmente está relacionado a uma situação de ruptura da família, diante da quebra dos laços existentes entre os genitores. Nestes casos, um dos genitores, geralmente aquele que detém a guarda do menor, por intermédio do fomento de mentiras, ilusões criadas para intervir de forma negativa na formação psicológica da criança, com o intuito de minar a relação existente com o outro genitor por falsear ao alienado a realidade que o cerca em relação ao outro genitor.
\end{abstract}

A alienação parental, portanto, encontra-se diretamente relacionada com a desvinculação dos genitores e o então desejo, consciente ou não, do genitor alienante de ter, sozinho, a melhor e maior relação pai/mãe-filho daquele círculo de pessoas que um dia formaram uma estrutura familiar.

\title{
2.1 DEFINIÇÃO DE ALIENAÇÃO PARENTAL SEGUNDO AS LEIS BRASILEIRAS
}

Descreve o artigo $2^{\circ}$ da Lei $\mathrm{N}^{\circ} 12.318$, de 26 de agosto de 2.010:

\begin{abstract}
Art. $2^{\circ}$ : Considera-se ato de alienação parental a interferência na formação psicológica da criança ou do adolescente promovida ou induzida por um dos genitores, pelos avós ou pelos que tenham a criança ou adolescente sob a sua autoridade, guarda ou vigilância para que repudie genitor ou que cause prejuízo ao estabelecimento ou à manutenção de vínculos com este.
\end{abstract}

Observa-se que o legislador, sabiamente, deixou claro que a alienação parental não necessariamente decorre de conduta do genitor da criança, ainda que esta hipótese seja a mais comum.

A mencionada lei, por meio do artigo transcrito, criou a possibilidade de qualquer pessoa que, por algum motivo ou circunstância, 
esteja com autoridade, guarda ou vigilância da criança alienada, arcar legalmente com as atitudes alienantes por ele praticadas.

Isso posto, pela leitura do artigo retro, fica fácil entender em que consiste a conduta alienadora, repudiada pela lei. Trata-se de: adolescente,

1 Interferência na formação psicológica - de criança ou

2 Promovida por aquele que possui a autoridade, guarda ou vigilância do menor,

3 Com o intuito de que o menor passe a repudiar algum dos genitores $\mathrm{OU}$

4 Que resulte em prejuízo ao estabelecimento de vínculo da prole com o genitor ou à sua manutenção.

\section{OFICINAS DE PARENTALIDADE}

As oficinas de parentalidade nada mais são que encontros liderados por psicólogos e mediadores, onde ocorrem diversas rodas de conversa, dinâmicas e brincadeiras voltadas à educação familiar.

Todas as atividades realizadas seguem as diretrizes estabelecidas pelas cartilhas entregues nos cursos de treinamento, e são voltadas à conscientização e orientação acerca dos impactos decorrentes da separação no relacionamento familiar, visando combater a alienação parental e ensinar os pais e filhos a lidar com essa nova fase da vida familiar, pós separação.

Em suma, conforme descreve o próprio material de instalação do projeto:

Oficina da Parentalidade é um programa educacional, preventivo e multidisciplinar, direcionado às famílias que enfrentam a fase de reestruturação familiar, motivada pela ruptura dos laços conjugais dos pais, com o intuito de auxiliar todos os seus integrantes a superarem as eventuais dificuldades inerentes a esta fase, sem maiores traumas, sobretudo para os filhos. (Cartilha de orientação dos voluntários do projeto)

\subsection{A QUEM SE DESTINAM}


O público alvo do projeto são genitores que apresentam algum conflito, jurisdicionalizado ou não, relacionado ao exercício da parentalidade, podendo o conflito ser relacionado à relação entre os pais ou entre os pais e filhos, à exemplo das situações de divórcio, dissolução de união estável, regulamentação ou alteração de guarda e regulamentação ou alteração de sistema de convivência, bem como os respectivos filhos menores de idade, na faixa etária de seis a dezessete anos de idade.

Ressalta-se que não só os pais podem participar das oficinas, mas também avós, padrastos, madrastas, principalmente quando estes se mostrarem responsáveis pela criança ou adolescente.

Os pais que apresentam algum conflito relacionado ao exercício da parentalidade dissociado da conjugalidade, assim como seus respectivos filhos menores, podem ser encaminhados para a Oficina em qualquer fase do processo judicial, ou até mesmo antes do seu início.

Note-se que a existência de acordo entre os pais, homologado ou não, não obsta sua participação no projeto, já que o principal objetivo do programa em questão não é a resolução do conflito separatório, mas sim a prevenção de novos conflitos e a harmonização e estabilização das relações familiares, a fim de manter ou restaurar a base emocional familiar.

É recomendado que todos os familiares participem da Oficina no mesmo dia, de forma que percebam, desde já, que devem prezar pela união, independentemente do rompimento do vínculo dos pais, pois, desta forma, será possível promover o bem-estar dos filhos.

No entanto, em algumas situações específicas, a distância dos familiares é necessária para preservação do bem-estar e até mesmo segurança dos membros da família, como é o caso de situações de abuso e/ou violência, em que se recomenda que os familiares sejam convidados para participarem da Oficina em datas distintas.

Não há grande formalidade no que se refere à elaboração do convite, podendo este ser feito por escrito, através de carta postal ou de Oficial de Justiça, ou mesmo oralmente, pelo Magistrado, pelo Conciliador e pelo Mediador, na própria audiência ou sessão de conciliação ou mediação, ou pelo Psicólogo e pelo Assistente Social, durante a realização do estudo psicológico ou social.

Contudo, embora algumas famílias sejam apenas convidadas a participar do projeto em questão, existem casos em que a pessoa que está cuidando do litígio percebe maior gravidade, julgando necessária, e não apenas importante, a participação. Nessas situações, os litigantes recebem 
intimação, sendo obrigatória a presença por todo o tempo que durar a oficina. Ao final, recebem certificado de participação, o qual deve ser entregue no CEJUSC na semana seguinte à da participação.

\subsection{FUNCIONAMENTO E OBJETIVOS DAS OFICINAS DE PARENTALIDADE}

As cartilhas de orientação dos voluntários preveem uma série de atividades a serem realizadas nos encontros. Contudo, é tolerada a modificação da ordem das dinâmicas, bem como a sua adaptação de acordo com o caso concreto, devendo o voluntário analisar o andamento do encontro a fim de aplicar a melhor sequência e abordagem.

Tem-se, então, as sugestões para o funcionamento das oficinas, as quais seguem, não necessariamente à risca, o seguinte padrão.

Chegados os participantes, estes são separados em dois grandes grupos: o de pais e o de filhos.

Entre os pais, formam-se dois grupos, de dez a vinte pessoas, que ocupam salas diferentes.

Para a garantia de um ambiente tranquilo, livre de eventuais brigas e discussões e para que a presença de um cônjuge não iniba o outro nos momentos em que se deve demonstrar as emoções, o ideal é que o casal não permaneça junto, na mesma sala.

Ainda assim, os grupos devem ser mistos, para que haja permuta de ideias e pontos de vista.

Por sua vez, na oficina dos filhos, a divisão também é feita em dois grupos, contudo, o critério para segregação é puramente etário, sendo divididas crianças de seis a onze anos e adolescentes, de doze a dezessete anos. Tal prática se justifica pela linguagem e métodos a serem usados durante o programa.

Ressalta-se que, considerando-se a dependência de voluntários, bem como da cessão de local para realização, as divisões podem ser feitas de forma variada, de acordo com a disponibilidade, sendo a forma acima reportada a ideal para melhor que haja melhor desempenho dos participantes. 
Uma vez separados os grupos, as atividades são iniciadas. A Oficina foi projetada para ser executada em um único encontro, com duração de cerca de quatro horas, contendo explanações feitas pelo(s) facilitador(es), apresentação de slides e vídeos, período para questionamentos, discussões e prática das habilidades desenvolvidas e, especialmente nas oficinas dos filhos, atividades lúdicas.

No que se refere aos pais, o projeto tem como principais objetivos o emponderamento para que tenham condições de protagonizar a solução de seus próprios conflitos, sem a necessidade de intervenção constante do Poder Judiciário, bem como a conscientização de responsabilidade pela sua vida e de seus filhos, apontando-lhes o impacto de suas condutas no desenvolvimento de sua prole e a possibilidade do exercício de uma parentalidade mais saudável e colaborativa.

Por sua vez, quanto aos menores, as oficinas buscam a criação de um espaço seguro para possam expressar seus sentimentos a respeito da separação de seus pais, bem como o fornecimento de estratégias para que consigam superar dificuldades inerentes à fase de reorganização familiar e se adaptem à nova realidade.

\section{$4 \quad$ EFICIÊNCIA DAS OFICINAS DE PARENTALIDADE}

Como anteriormente explanado, o projeto ora estudado é impulsionado única e exclusivamente pelo trabalho de voluntários. Diante de tal circunstância, existe grande dificuldade no acompanhamento processual dos casos em que houve participação dos genitores nas Oficinas.

Assim sendo, diante da insuficiência de organizadores, não se é possível, ao menos por ora, obter dados concretos acerca das mudanças processuais trazidas pela participação no projeto.

Conforme pontuado pela organizadora das Oficinas na Comarca de Ribeirão Preto/SP, a consequência almejada é a efetiva mudança no comportamento dos genitores, de forma que os voluntários do projeto buscam, em primeiro plano, uma melhora comportamental no relacionamento genitor-rebento. As consequências processuais, embora não possam ser medidas em números precisos, são consequências naturais das conquistas alcançadas pelas reflexões propostas pelos instrutores no momento de participação. 
Da mesma forma que não é possível o acompanhamento processual, não há como se fazer acompanhamento psicológico individualizado com as famílias participantes do projeto.

Não existem psicólogos suficientes para análise posterior ao acontecimento da Oficina, pelo que os resultados obtidos são medidos por meio da comparação entre os discursos iniciais dos genitores e das crianças com seus discursos finais.

Inclusive, é notável a divergência no discurso dos participantes, em especial dos genitores, que, em primeiro momento, fazem uso de qualquer oportunidade de fala para denegrir a imagem do ex-cônjuge, apontando diversos erros por eles cometidos. Diferentemente, ao final, é possível perceber discursos de autorreflexão, até mesmo com a indicação de erros próprios e situações que podem ser melhor tratadas por ambas as partes conflitantes.

Diante disso, ainda que não seja possível a demonstração de mudanças pontuais nos relacionamentos, são apresentados diversos indícios de que os genitores ali presentes compreenderam de fato a relevância de suas atitudes na formação de seus filhos, sendo justo considerar que as oficinas realmente são capazes de trazer mudanças positivas para a vida das famílias com pais separados.

\section{$5 \quad$ EFICÁCIA DAS OFICINAS DE PARENTALIDADE}

Em seu funcionamento atual, é possível perceber que, embora o projeto alcance seu objetivo base, ainda há muito para ser melhorado.

A utilização exclusiva do voluntariado é grande empecilho no crescimento das oficinas, na medida que limita o número de participantes, uma vez que a quantidade de instrutores disponíveis é limitada.

O horário em que ocorrem também não é favorável para a atração de novos voluntários ou mesmo para a participação dos litigantes convidados. Realizadas na última quinta feira de cada mês, no caso da Comarca de Ribeirão Preto, as oficinas ocorrem no período da tarde, tendo duração total de 04 (quatro) horas. Tal fato constitui grande obstáculo para as partes que trabalham, tendo, inclusive, sido presenciado caso de necessidade de saída antes da finalização em razão de trabalho. As crianças, igualmente, necessitam faltar da escola no dia do projeto. 
Por fim, necessário ressaltar a impossibilidade do tão importante acompanhamento processual e psicológico das famílias após a participação, o que não é possível ser feito nos moldes atuais. É compreensível que os poucos voluntários disponíveis não dispõem de tempo e qualificação suficiente para tanto, fato este que reforça o argumento retro, de que a utilização exclusiva do trabalho voluntário não de mostra suficiente para abarcar projeto de tamanho propósito.

Com o fim de amenizar as dificuldades apontadas, percebe-se que a única alternativa é a contratação de profissionais habilitados para condução e acompanhamento das famílias participantes do projeto.

Com a presença de profissionais do direito, seria possível melhor instrução a respeito da problemática da alienação parental, bem como conscientização das formas processuais de amenização dos conflitos.

Ainda, a contratação de psicólogos capacitados possibilitaria uma melhor avaliação individual e conjunta dos participantes, de forma a conduzir os assuntos abordados de acordo com a necessidade de cada grupo.

Com profissionais de ambas as áreas, seria possível o devido acompanhamento dos litígios, de forma a orientar os genitores sempre que necessário, propondo-se um acompanhamento a longo prazo, em detrimento de instrução pontual.

Ademais, é de suma importância a disponibilização de local adequado para realização do projeto, o qual deve dispor de espaço suficiente para a acomodação dos participantes e ouvintes.

Todas as melhorias sugeridas possuem, em última análise, o condão de trazer resultados palpáveis ao projeto, de forma a, acima de tudo, incentivar a sua expansão.

É claro que todas as medidas sugeridas importam em grandes gastos, não sendo viável se esperar que a organização do projeto arrecade tamanha receita.

Isso posto, vislumbra-se a necessidade de apoio dos Tribunais Estaduais, de forma que, a curto prazo, poderia ocorrer o investimento em Oficinas de determinadas Comarcas espalhadas pelo país, nas quais seria possível o estudo minucioso dos resultados obtidos.

Com isso, sendo positivos os resultados, haveria a possibilidade de investimento gradual nas demais cidades brasileiras, de forma a "curar" as raízes do problema ao invés de abarrotar o judiciário com ações 
reincidentes de guarda, alimentos e alienação parental, para as quais são apresentadas soluções sensíveis e temporárias.

\section{CONSIDERAÇÕES FINAIS}

A partir do momento em que o divórcio deixa de ser tabu e ocorre em gigantescas proporções, faz-se necessário analisar e cuidar das consequências psicológicas que podem ser trazidas às partes envolvidas nessa separação que, em vezes, revela-se traumática: os pais e os filhos.

O direito, embora não seja a área que cuida diretamente dos fatores psicológicos e comportamentais, possui a responsabilidade de utilizar dos artefatos legais para evitar maiores litígios. Explica-se:

$\mathrm{Na}$ medida em que é o direito que se responsabiliza pela estruturação da família após o divórcio, é preciso que esta área se preocupe com as consequências fáticas que virão da decisão da guarda. Primeiro, é preciso levar em consideração a forma como a criança, quem deve ser a principal protegida, reagirá à nova vida e ao novo lar. Depois, é necessário avaliar como a relação entre a criança e os pais está afetando o desenvolvimento mental do menor. Por isso o direito deve se unir à psicologia.

E é o que é feito nas Oficinas de Parentalidade.

A partir do que foi observado ao longo da elaboração desta pesquisa, foi possível perceber que, juntas, as duas áreas caminham para uma melhor qualidade de vida das famílias que passam por divórcios críticos, de extrema litigiosidade.

O juiz, para decidir sobre a guarda de forma a evitar futuros litígios sobre alimentos, visitas, entre outros, precisa que haja uma educação da família no sentido de compreender que as decisões judiciais visam, primordialmente, o bem-estar do menor. No mesmo sentido, precisa que os pais entendam a importância do respeito ao que foi decidido e, ainda melhor, entendam como suas atitudes afetam a prole.

Com uma compreensão por parte dos pais de toda essa sistemática que existe por traz de uma simples decisão de guarda, é possível que haja melhor respeito a ela, de forma a zelar pelo interesse de todas as partes, evitando novas brigas e desconfortos desnecessários. 
As Oficinas de Parentalidade são precisas ao trazer essa educação para toda a família, mostrando para os filhos que eles não devem se colocar no meio das brigas dos pais e, para os pais, que suas discussões em relação ao filho possuem consequências diretas no crescimento e na personalidade do menor.

O trabalho é desenvolvido de forma a evitar que as crianças sejam colocadas em situação de alienação parental, sendo que as diversas dinâmicas realizadas nos encontros são voltadas para a conscientização.

Infelizmente, com a falta de recursos, não é possível o acompanhamento das famílias após a participação do projeto, o que faz com que seja impossível medir os resultados práticos dos encontros realizados.

No entanto, em conversa com as psicólogas voluntárias, tem-se sua opinião profissional de que, ainda que não saibamos o destino daquelas famílias, é possível perceber uma mudança em seu comportamento ao finalizarem sua participação. Segundo elas, é nítido o impacto psicológico causado pelas informações que lhes foram apresentadas, de forma que resta apenas acreditar que tal impacto tenha sido suficiente para mudar a forma que tratam os conflitos familiares.

Para a obtenção de números precisos, é preciso que haja grande investimento por parte dos tribunais, de forma a reunir quantidade suficiente de profissionais capacitados para acompanhamento legal e psicológico das famílias participantes e, por outro lado, para que haja esse investimento, necessita-se que os tribunais notem os efetivos resultados trazidos pelo projeto, o que cria um ciclo vicioso.

A única forma, por hora, de ajudar o projeto a crescer é através da divulgação e recrutação de voluntários.

As oficinas possuem objetivos maravilhosos à luz do direito e da psicologia, e seus resultados, ainda que não possam ser medidos em números, são visíveis.

Assim, é preciso que cada vez mais pessoas tenham conhecimento e se juntem ao projeto, de forma que cada vez mais famílias possam ser educadas e viver em maior harmonia, ainda que após sua dissolução.

\section{REFERÊNCIAS BIBLIOGRÁFICAS}


ALMEIDA JÚNIOR, Jesualdo. Comentários à Lei da Alienação Parental - Lei nº 12.318, de 26 de Agosto de 2010. Revista Síntese Direito de Família, vol. 12, nº 62, out/nov, 2010 .

CASSETARI, Christiano. Guarda compartilhada: uma análise da Lei 11.698/2008. In: COLTRO, Antônio Carlos Mathias; DELGADO, Mário Leuiz (coords.). Guarda Compartilhada. São Paulo: Editora Método, 2009.

CEZAR-FERREIRA, Verônica A. da Motta. Família, separação e mediação - uma visão psicojurídica. 2 ed. São Paulo: Ed. Método, 2007,

CORREA, Marise Soares. A História e o Discurso da Lei: O Discurso Antecede à História. Tese de doutorado em História (Pontifícia Universidade Católica do Rio Grande do Sul, Faculdade de Filosofia e Ciências Humanas, Programa de pós-graduação em história, doutorado em história). Orientadora Profa. Ruth Maria Chittó Gauer. Porto Alegre, 2009.

CROENINGA, Giselle Câmara. Guarda compartilhada - a efetividade do poder familiar. In: COLTRO, Antônio Carlos Mathias; DELGADO, Mario Luiza (coords). Guarda Compartilhada. São Paulo: Editora Método, 2009.

FIGUEIREDO, Fábio Vieira; ALEXANDRIDIS, Gergios. Alienação Parental. São Paulo: Saraiva, 2011.

CONSELHO NACIONAL DE JUSTIÇA. Alienação parental: Ações crescem em 85\% na justiça mineira em 2017. Disponível em: http://www.cnj.jus.br/noticias/judiciario/86643alienacao-parental-acoes-crescem-85-na-justica-mineira-em-2017. Acesso em 13/05/2019.

Autor desconhecido. Aumento do número de processos por alienação parental mostra que famílias estão mais informadas, diz OAB. Disponível em : https://g1.globo.com/sp/saocarlos-regiao/noticia/aumento-do-numero-de-processos-por-alienacao-parental-mostraque-familias-estao-mais-informadas-diz-oab.ghtml. Acesso em 10/06/2019

IBGE - INSTITUTO BRASILEIRO DE GEOGRAFIA E ESTATÍSTICA. GUARDA DE FILHOS MENORES. Disponível em:

https://seriesestatisticas.ibge.gov.br/series.aspx $?$ no $=10 \& o p=0 \& v \operatorname{codigo}=\mathrm{RGC} 403 \& \mathrm{t}=$ divo rcios-responsavel-pela-guarda-filhos-menores. Acesso em 03/07/2019.

IBGE - INSTITUTO BRASILEIRO DE GEOGRAFIA E ESTATÍSTICA. SEPARAÇÕES JUDICIAIS. Disponível em: https://sidra.ibge.gov.br/pesquisa/registrocivil/quadros/brasil/separacoes-judiciais-serie-suspensa.

LEVY, Fernanda Rocha Lourenço. Guarda dos filhos: os conflitos no exercício do poder familiar. São Paulo: Atlas, 2008, p.45 
RODRIGUES, Leonardo Bittencourt. A Alienação Parental no Ordenamento Jurídico Brasileiro Enquanto da Tramitação do Projeto de Lei No 4.053/2008. Revista Projeção, Direito e Sociedade. V.2. n. 1. p. 46-55. Mai 2011.

TRINDADE, Jorge. Manual de Psicologia Jurídica Para Operadores do Direito. $4^{\mathrm{a}}$ ed. verificada, atualizada e ampliada. Porto Alegre: Livraria do Advogado Editora, 2010. 